\title{
Relatos de Experiências da participação de Mato Grosso no Technovation Challenge 2017
}

\author{
Pedro Clarindo da Silva Neto ${ }^{1}$, Monique Casagranda ${ }^{2}$ \\ ${ }^{1}$ Instituto Federal de Educação, Ciência e Tecnologia de Mato Grosso - Campus \\ Avançado Tangará da Serra (IFMT) \\ Rua 28, 980, Vila Horizonte - 78.300-000 - Tangará da Serra - MT - Brasil \\ ${ }^{2}$ Instituto Federal de Educação, Ciência e Tecnologia de Mato Grosso - Campus \\ Campo Novo do Parecis (IFMT) \\ Rodovia MT 235, Km 12 - 78.360-000 - Campo Novo do Parecis - MT - Brasil \\ \{pedro.neto@tga, monique. casagranda@cnp\} ifmt.edu.br
}

\begin{abstract}
This paper presents the participation of the Mato Grosso state in the Technovation Challenge in the 2017 edition. By the fact of most professionals in the area of computing are men, participation in the event is intended to influence the insertion of women in technology. By this, girls from 10 to 18 years old, elementary and middle school, can have their first contact with the area, with the creation of mobile applications and, from there, create bonds and pursue a career.
\end{abstract}

Resumo. Este artigo apresenta a participação do estado de Mato Grosso no Technovation Challenge na edição de 2017. Pelo fato da maior parte dos profissionais na área de computação serem homens, a participação no evento tem a intenção de influenciar a inserção de mulheres na tecnologia. A partir desta competição, meninas de 10 a 18 anos, do ensino fundamental e médio, podem ter o seu primeiro contato com a área, com a criação de aplicativos móveis e, a partir daí, criar vínculos e seguir carreira.

\section{Introdução}

De maneira recorrente, encontra-se em jornais e sites de notícias a existência de vagas para profissionais na área de TI. Este profissional, sempre disputado por grandes empresas, acaba empregado antes mesmo de se graduar. Atualmente, existem nas universidades, diversas feiras e eventos nas quais empresas de grande porte buscam novos colaboradores.

Figueiredo, Silva Neto e Maciel (2016) informam que pesquisas dentro do ambiente acadêmico, mais precisamente em cursos de Computação, revelam que mulheres ainda são minoria dentro das turmas e que houve uma regressão nesse número, que em 1991 era de 34, $9 \%$ e, em 2013, data do último censo do INEP, era de apenas $15,53 \%$.

Com o intuito de criar oportunidades que despertem, novamente, o interesse das mulheres pelos cursos de computação, diversas iniciativas aparecem no âmbito acadêmico e profissional. Dentro da própria Sociedade Brasileira de Computação 
(SBC), tem-se o Women in Information Technology (WIT) que, posteriormente, deu origem ao programa Meninas Digitais, hoje um programa chancelado pela SBC.

O Programa Meninas Digitais é direcionado às alunas do ensino médio/tecnológico, para que conheçam melhor a área de Informática e das Tecnologias da Informação e Comunicação, de forma a motivá-las a seguir carreira nessas áreas [SBC MT 2015]. Diferente de outras ações, o programa Meninas Digitais tem como público-alvo as meninas que cursam no ensino médio e estão em uma fase de escolha de carreira.

Outra iniciativa que possui público-alvo semelhante é o Technovation Challenge. O Technovation é uma competição de tecnologia para meninas de ensino fundamental e médio, que é organizado pela Iridescent, uma organização educacional americana sem fins lucrativos, que capacita profissionais das área de ciências exatas a disponibilizar educação STEM $^{1}$ para meninas carentes, crianças e seus familiares [Iridescent 2017].

Dentro dessa competição, as meninas participantes são levadas a criar aplicativos para dispositivos móveis que resolvam um determinado problema relacionado a uma área social (pobreza, saúde, educação, entre outras). Além disso, devem elaborar um plano de negócios correspondente a este aplicativo, no qual serão descritas as funcionalidades e como o mesmo irá gerar lucro.

Neste artigo, serão abordadas as ações criadas pelo IFMT - Tangará da Serra e Campo Novo do Pareci,s juntamente com suas alunas no Technovation Challenge 2017, e as estratégias para aumentar as possibilidades das equipes seguirem para a próxima fase do evento.

\section{Technovation Challenge}

Segundo a Technovation Brasil (2017), a competição é, atualmente, a maior do mundo para meninas em tecnologia. O programa começou em 2009, em Mountain View, Califórnia. Em 2013, foi aberto pela primeira vez para outros países, e contou com a participação de mais de 600 meninas de países como Índia, China, Indonésia, Inglaterra, Ucrânia, Gana, Nigéria e Brasil.

A competição possui seu currículo dividido em 12 semanas, tendo foco em um tema diferente a cada semana. Durante este período, são recomendadas as atividades referentes às etapas de programação do aplicativo, a criação do plano de negócios, a produção dos vídeos de apresentação do projeto (pitch) e o vídeo de demonstração de funcionamento do aplicativo [Technovation 2017].

As meninas são orientadas por mentores (coach), que lhes auxiliam nas tarefas. Esses mentores são voluntários, que podem ser da mesma cidade e escola que as meninas ou podem estar em locais diferentes, realizando uma mentoria virtual. Tanto os mentores quantos as alunas se cadastram no sistema que administra o evento, o $M y$ Technovation Challenge ${ }^{2}$.

\footnotetext{
${ }^{1}$ STEM (Science, Technology, Engineering and Mathematics)

${ }^{2}$ my.technovationchallenge.org
} 
Após a inscrição no evento, as meninas se organizam em equipes de até cinco componentes para a formação de um time. O time é classificado como Sênior ou Júnior, baseado na idade da participante mais velha. Essas meninas podem ter de 10 a 18 anos, sendo que times com participantes a partir de 14 anos são considerados Sênior.

Uma vez que as alunas estão cadastradas e estão participando de um time com um mentor, também cadastrado, lhes auxiliando, a plataforma permite que os times comecem a submeter seus materiais.

Na Figura 1, pode-se observar às visões de mentor e da aluna do ambiente de submissão dos materiais. Esta figura mostra o ambiente dos times, com o nome das participantes, dos mentores e suas fotos. Este ambiente é utilizado para a submissão dos trabalhos efetuados e os seus detalhes, como a plataforma utilizada para desenvolvimento do aplicativo, o código fonte e o plano de negócios do mesmo.

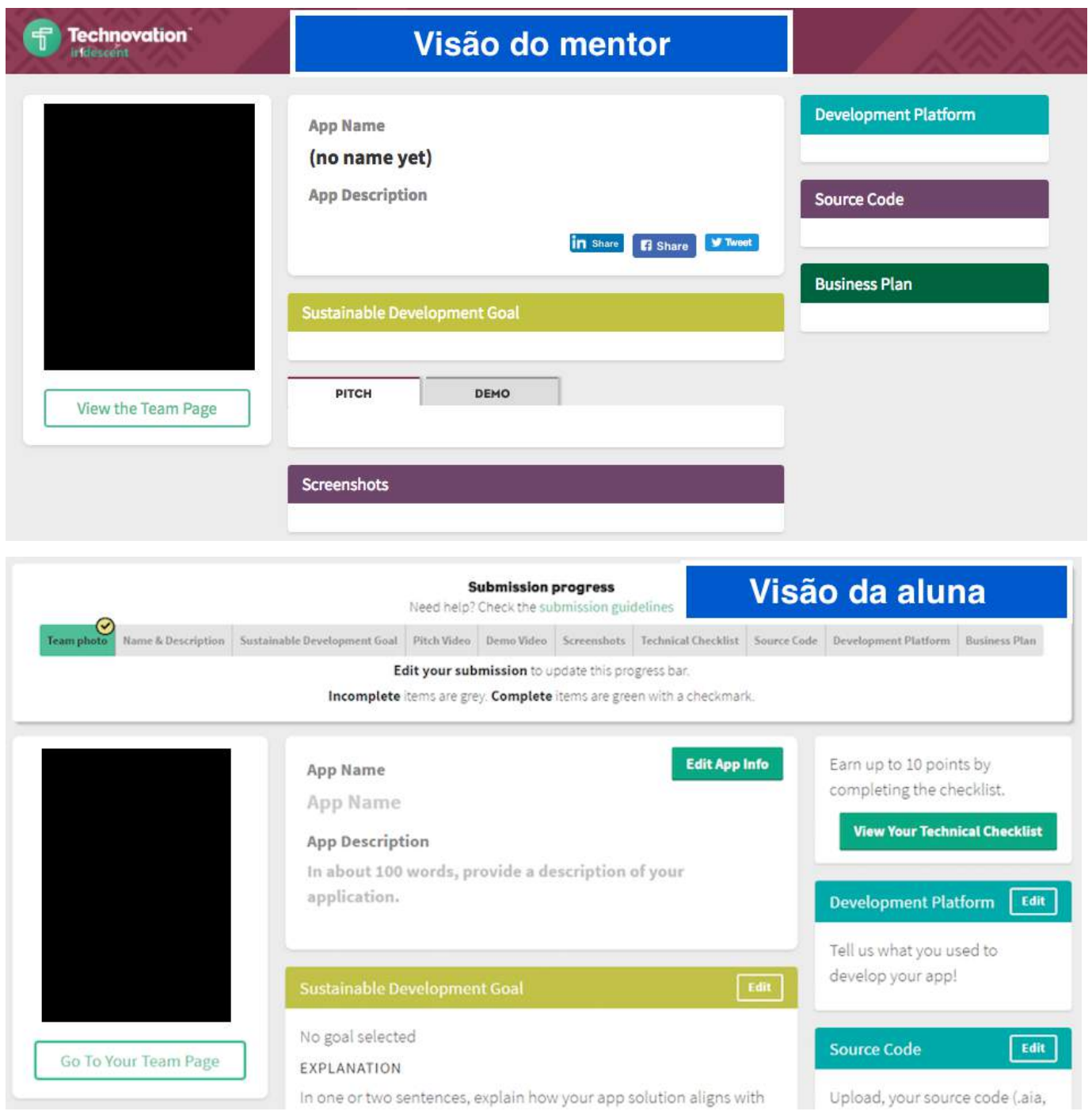

Figura 1. Ambiente Technovation (visão de mentor e da aluna) 
Com o ambiente virtual devidamente preenchido até a data limite, existem duas formas de avaliação dos projetos: virtualmente, por juízes que se cadastram no sistema, e por apresentações, chamadas de pitchs regionais, nas quais as equipes, presencialmente, apresentam às ideias para juízes que assistem às apresentações e avaliam os projetos.

\section{Participação de Mato Grosso na edição de 2017}

Em 2016, o estado de Mato Grosso participou do Technovation com duas equipes, sendo uma de Cuiabá, com alunas de escolas estaduais, e outra do município de Tangará da Serra, com alunas do IFMT. Neste ano, o estado não conseguiu realizar um pitch regional devido a quantidade de equipes, consequentemente, participaram do julgamento virtual com as demais equipes do país, que não participaram de eventos regionais. Apesar de receber uma boa pontuação, nenhuma das equipes obteve êxito em seguir para próxima fase do certame.

Com a participação de 2016, outras meninas tomaram conhecimento da competição e tiveram interesse na mesma. Além disso, foram realizadas oficinas introduzindo os conceitos de desenvolvimento móvel e apresentando o Technovation Challenge para meninas de outras escolas no estado.

Essas oficinas foram executadas como ações do Meninas Digitais, que funciona no IFMT como um projeto extensionista, no qual alunas dos campi e de outras escolas da cidade participam de reuniões semanais, realizando atividades que as estimulem a seguir carreira na computação.

Na edição de 2017, o estado de Mato Grosso está participando com dez equipes Sênior e uma Júnior, proveniente de alunas de ensino médio dos campi de Tangará da Serra e de Campo Novo do Parecis, além de alunas do ensino fundamental da cidade Tangará da Serra. Com esta configuração, o estado está apto a realizar o pitch regional para a modalidade Sênior. A equipe Júnior participará do julgamento virtual, por ter apenas uma equipe.

\section{Conclusões}

A partir do Technovation Challenge, é apresentada para meninas de ensino fundamental e médio uma oportunidade de conhecer e se integrar ao mundo da tecnologia, de forma direta, participando de um evento de abrangência internacional. Esta competição é uma ótima aliada dentro das ações de programas como o Meninas Digitais. A cada edição do evento, o mesmo atinge um raio maior de disseminação e mais meninas têm a oportunidade de conhecer e desenvolver ligações com a tecnologia.

Além disso, as habilidades das participantes são aprimoradas em relação ao desenvolvimento de aplicativos móveis com as oficinas que são oferecidas, em relação ao uso de padrões para desenvolvimento dos mesmos e em relação ao trabalho em comunidade, visto que o desafio é realizado em grupos e existem reuniões semanais. Em Mato Grosso, a participação vem aumentando e para as próximas edições, pretendese ampliar, ainda mais, a quantidade de equipes no estado. 


\section{Referências}

Figueiredo, K. S., Silva Neto, P.C., Maciel. C. (2016) “ Meninas Digitais Regional Mato Grosso: Práticas Motivacionais no Ensino Médio para a Equidade de Gêneros nas Carreiras e Cursos de Computação e Tecnologias”, WIT - Woman In Information Technology in Anais do XXXVI congresso da sociedade brasileira de computação, p. 2702-2705.

SBC (2015) "Programa Meninas Digitais", https://sbcmt.wordpress.com/meninasdigitais, March.

Technovation (2017) “Calling all innovators", http://technovationchallenge.org/getstarted/, March.

Technovation Brasil (2017) "Sobre nós", http://www.technovationbrasil.org/sobre-nos, March. 